counts of how they teach and how they write, we can begin to see our work as part of a creative process, making something new, original, never before seen or understood in that particular way.

Because a focus on process is central to both creative writing and creative research, we can each find help for our work when we hear and read writers on writing and teachers on teaching writing.
Stafford's particular approach may not be appropriate or helpful for everyone, but I believe all librarians working with researchers can find inspiration and help in the experiences of creative writers and teachers of creative writing. As the importance of creativity for librarians is recognized, we may even see some new and creative subject headings in Library Literature.

\title{
Managing innovation and innovators
}

\author{
By Fred M. Amram \\ Professor of Speech Communications, General College \\ University of Minnesota-Twin Cities
}

Lots of time and money are spent fostering creativity in the workplace. Witness ACRL President Joanne Euster's article, "Creativity, Innovation and Risk-Taking" in the Juily/August 1987 issue of $C \& R L$ News. Special efforts are made to help librarians, teachers, engineers, social workersmost employed persons-to invent new products and processes. We are told to "find a better way."

Much of the effort will be wasted, however, if the work environment in which employees find themselves is not conducive to new ideas and risktaking. No amount of employee skill and attitude development will enhance creativity unless the environment supports this effort.

Three key factors in the work environment have special influence on creativity: people, space, and time. While all three are interrelated, each will be discussed independently.

There are three categories of people in the environment who may enhance or inhibit creativitythe self, peers, and supervisors. The self is certainly the most severe critic. Who knows better which "put down" will be most effective? Who remembers best, consciously and subconsciously, the entire life history of failures? Training works best when it teaches the individual to try, to risk, to dare. Training works best when it demonstrates to the individual how one blocks creativity with unnecessary habits, fears, conformity, fixations, and all the other self-inhibitors. Innovation requires self-confidence-the "I think I can" attitudewhich comes largely from remembered success experiences.

Ultimately the motivation to risk (to want to try) requires feeling good about oneself and that comes from remembered success experiences. Good training and good management help people to feel successful and discover personal strengths.

A reward system that endorses effort as well as winners will help ensure success experiences. It is noteworthy that not every idea is a good idea, but without new ideas there is no innovation. Not every oyster contains a pearl.

Reward systems should allow for individual differences and preferences. Just as we each know our failures we also know best what makes us feel successful. But the encouragement of rewards may not be enough. A limited amount of pressure may bring out the best. "I expect you to be creative" says that I believe in you. Nothing enhances selfconfidence more than the confidence of others.

Other people in the work environment affect the individual's creativity as well as oneself. Peers surely have more influence on one's sense of creativity than bosses, and they provide a real opportunity to collaborate as well as a sense of our selfworth.

American culture is often not conducive to collaboration. We are a competitive people. In the academic as well as the corporate setting we are afraid that the other person may get the patent, the reward, the step up the elusive ladder to success. Again and again scholars report that they dare not share an idea until it's in "final form." Scientists report that they dare not ask advice-technical or procedural-for fear that an idea will slip away. And yet none of us is expert in all things. We need our colleagues to develop our ideas, to enhance our ideas, and to test our ideas. Consequently, American libraries must develop a collaboration system that encourages and teaches individuals to use one another's information, insights, and skills.

For one thing, libraries should develop group reward structures. If two or three individuals participated in an innovation, each should share in the reward-either equally or in proportion to their contribution. In some cases whole departments might be rewarded even though not all individuals contributed to the idea. Such group rewards recognize the importance of peers as emotional support 
for innovators and emphasize an organizational committment to a creativity program. In some cases peers are the best judges of who should receive rewards and what forms they should take.

Bosses may not have as important an impact on creativity as peers do, but supervisors, managers, and directors are an important part of the work environment and do have a major opportunity to enhance or inhibit innovation. Bosses have "referent power." That means they act as models of how to behave. Bosses can be models of creativity, risktaking, and intellectual daring, or they can be models of stagnation, self-protection, and intellectual boredom. This is not to say that bosses must be exceptionally creative; it means that they must model an openness to new ideas, an enjoyment of challenges, and a tolerance for ambiguity. Supervisors who enhance the creativity of others do not insist that their solutions are best. Creativity requires the freedom to design innovative ways to meet objectives.

The second key factor is place. The library, like the laboratory, is usually a place for testing ideasnot for having them. Perhaps a "think space" needs to be provided. A recent survey in one of this country's top 50 corporations asked technical and scientific employees to identify what, in their work environment, inhibits creativity. The number one response was noise, visible as well as audible. Not all employees need private offices, but they do need private think spaces-quiet places where they can formulate hypotheses and incubate ideas.

Quiet spaces are, however, not enough. Public spaces are necessary for the complex process of creative problem-solving that involves collaboration, testing, and implementation.

The third critical factor is time. Going to a file cabinet to pull out last month's solution may seem time-effective, but last month's solution may not solve this month's problem. File cabinet solutions rarely provide an innovative product, process, manufacturing system, or sales program.

Time management programs are often helpful and may bear repeating periodically. Such programs generally require participants to document in detail exactly how time is spent. Unnecessary activities, unwanted interruptions, and inefficiencies are brought to light. Creativity applied to personal work habits and work distribution can save substantial time that may be reinvested in more creative efforts.

Employees report greater benefits from large blocks of time (an afternoon, a day, a retreat) than from occasional random snatches of time.

Creativity is not easy nor is it cheap; however, it is a good investment. The rewards are twofold: increased employee satisfaction, and the ability to improve service in a world of radical change and incredible technological development.

\section{From THE HISTORIC NEW ORLEANS COLLECTION}

\section{Indispensable Reference \\ " ...an enormously useful reference work ...' \\ - William T. Alderson Old Salem, Inc. \\ Over 2,700 artists. 488 pages. Hardback. $\$ 39.95$ \\ ISBN 0.917860-23.3 \\ LCCN 87-80477}

The Historic New Orleans Collection 533 Royal Street $\bullet$ New Orleans, LA 70130 (504) $523-4662$
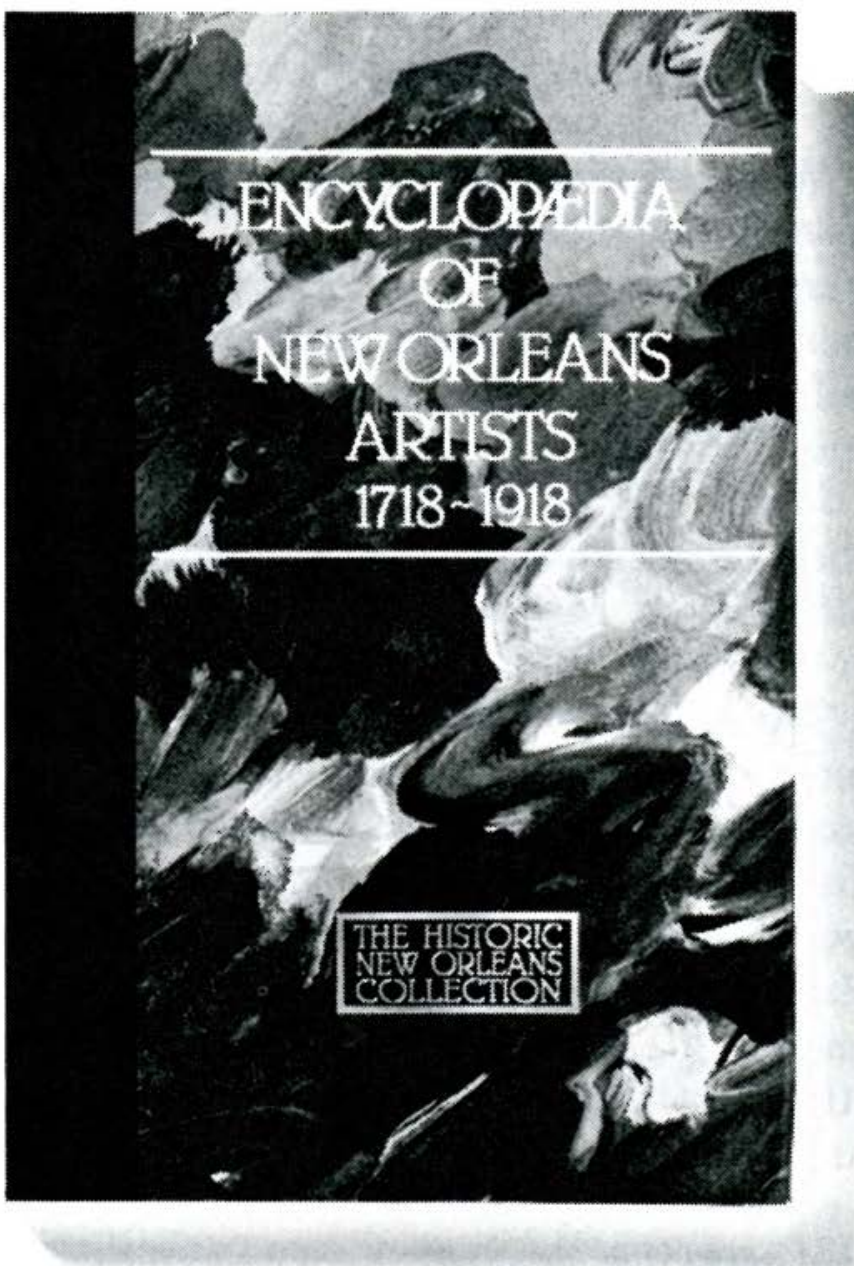


\section{WESS Florence Conference}

ACRL's first overseas conference within recent memory will take place April 4-8, 1988, in Florence, Italy, where the ACRL Western European Studies Section will consider: "Shared Resources, Shared Responsibilities: Libraries and Western European Studies in North America and Western Europe." The conference will focus on aspects of librarianship involving European materials and libraries, including acquisition of European materials; online databases of European materials; European government documents; translations; non-book formats such as microformats and films; European political and social movements; and fine arts library resources from Europe.

The organizers of the Conference are Assunta Pisani, Harvard University; Charles Fineman, Northwestern University; and Anna Perrault, Lou- isiana State University. They have planned both an ambitious program with outstanding European and North American speakers and a travel package that makes attendance at the conference attractive in price as well.

Arrangements for air travel, hotels, and ground transportation must be made separately. Information will be sent to you upon receipt of your registration. Although the travel package is not yet firm, the estimated cost of the airfare will probably be $\$ 555$ (New York departures) or $\$ 655$ (Los Angeles departures), depending on the exchange rate. The estimated cost of the hotel and ground transportation package, including seven nights lodging (double occupancy) will be approximately $\$ 500$. Registration for the four-day Conference will be $\$ 150$ until December 31, 1987, and \$225 after Jan-

\section{REGISTRATION FORM}

"Shared Resources, Shared Responsibilities:

Libraries and Western European Studies in North America and Western Europe"

ACRL/WESS Conference-Florence, Italy-April 5-8, 1988

Name:

$\begin{array}{lll}\text { Last } & \text { First } & \text { Middle }\end{array}$

Institution:

Address:

City: State: Zip: Country:

Telephone:

Registration fees:

$\$ 150$ until December 31, 1987

$\$ 225$ January 1, 1988, and after

Form of payment: check, payable to American Library Association American Express Card \# Visa or MasterCharge

$\#$ Exp. date: Exp. date:

Plese mail this form to:

ACRL/WESS Conference

50 E. Huron St.

Chicago, IL 60611 
uary $1,1988$.

Partial payment for these arrangements will be due December 31, 1987; full payment will be due in February 1988. JoAn Segal, ACRL executive di- rector, is staff liaison for the Conference.

To register, complete the form on the previous page and send it to ACRL/WESS Conference, 50 E. Huron St., Chicago, IL 60611.

\title{
Need a change? Try an exchange
}

\author{
By Nancy J. Keane \\ Cataloger \\ University of Vermont
}

\section{Trading places with one's counterpart in the Republic of Ireland.}

\begin{abstract}
A
I began to pack my bags and prepare to leave for a one-year exchange, it seemed that this moment had been a long time coming. As a matter of fact, it had been almost two years. There were times when I felt as if it never would arrive. When I mentioned my plans to colleagues, the most frequently asked question was not why I was going, but how I went about arranging an exchange. Each exchange is a unique situation with its own problems. However, I hope my experience will shed some light on the process for those of you who are contemplating an exchange.

Let me first touch upon the "why" of exchanges. Job exchanges have been around for a long time and have taken many forms. Exchanges range from international to intralibrary. They benefit the librarians who are involved in the exchange, those who have dealings with the guest librarian, and the institutions involved. Exchanges foster interinstitutional cooperation, information sharing, networking, and standardization. They offer an exciting way for the librarians involved to "recharge" their batteries.

Now that you are convinced that exchanges are worthwhile, how do you arrange one? The first part of the process requires one to think long and
\end{abstract}

hard about this idea. Are you prepared to leave your job, home, friends, relatives, etc., for an extended amount of time? Do you really want to go through with this experience? Then there are the arrangements to deal with. Not only do you have the frustrations and costs involved in setting up an exchange, but you must also be able to convince your administrators that the exchange will benefit both librarians and institutions. Without strong support from your administrators, you may not be able to get through the arrangements. They will be called upon time and time again to provide documents, recommendations, phone calls, etc. The University of Vermont has no formal mechanism for a job exchange so I was left to find my own way through the process. This was both good and bad. It was good in that I did not have strict guidelines that must be followed so I was able to tailor the exchange to meet my needs. It was bad in that I had to work by trial and error. After I had convinced myself of the advantages of the exchange, I then sought approval from my supervisor. The major stipulation set out by the University was that the exchange partner must be an experienced cataloger from an academic library.

With my goal set and approval from my supervi- 